\title{
Physiological Behaviour and Yield Performances of Hybrid Rice at D ifferent Planting D ates in Aus Season
}

\author{
M M Haque*1, H R Pramanik² and J K Biswas³
}

\begin{abstract}
Two field experiments were conducted in 2009 and 2010 to evaluate some physiological traits and yield of three hybrid rice varieties (BRRI hybrid dhan2, Heera2, and Tia) in comparison to BRRI dhan48 in A us season. The experiments involved four planting dates (1 A pril, 16 A pril, 1 May and 16 May). Compared to BRRI dhan48, hybrid varieties accumulated greater shoot dry matter at anthesis, higher flag leaf chlorophyll at 2, 9, 16 and 23 days after flowering (DAF), flag leaf photosynthetic rate at $2 \mathrm{DAF}$ and longer panicles. However, hybrid varieties demonstrated smaller remobilization of shoot reserve to grain and photosynthetic rate of its flag leaf at 9 and 16DAF than BRRI dhan48. Heera2 and BRRI hybrid dhan2 maintained significantly higher chlorophyll a:b ratio over Tia and BRRI dhan48 at 2, 9, 16 and 23 DAF in their flag leaf. Shoot reserve remobilization to grain exhibited higher degree of sensitivity to rising of minimum temperature in the studied hybrids compared to the inbred. Inefficient photosynthetic activities of flag leaf and poor shoot reserve translocation to grain resulted poor grain filling percentage in the test hybrids. Consequently the studied hybrids showed significantly lower grain yield (ca. 36.7\%) as compared to inbred BRRI dhan48, irrespective of planting date in Aus season.
\end{abstract}

Key Words: BRRI hybrid dahn2, flag leaf, grain filling, translocation.

\section{INTRODUCTION}

Yearly increment of rice production in Bangladesh needs to be sustained to feed her ever increasing population. But there is population Yearly increment of rice production in Bangladesh needs to be sustained to feed her ever a little scope to increase rice area (Sarker et al., 2008) rather agricultural land is declining @1\% per annum (BBS, 2011). However, the recent yield level of modern rice varieties has been reached to plateau (Bhuiyan, 2002). For breaking the yield ceiling of conventional varieties, hybrid rice is a viable option and appropriate strategy (Kumar et al., 1998). It can produce 15 - 20\% higher yield over the conventional semi-dwarf inbred variety (Longping, 2004 and Julfiquar, 2009). Hybrid rice has been introduced in Bangladesh during the last eight years (M asum, 2009). It has already gained positive experience in Boro season and drawn much attention of the stakeholders. Recently, a few hybrid varieties are also recommended and cultivated in T. A man season. But report on hybrid rice cultivation in A us season is scanty. So, it is needed to generate information on agronomic and physiological performance of hybrid rice varieties for extending its cultivation in A us season. A non-monetary input, planting date is one of the most important factor influencing the growth and yield of rice. Planting date determines the flowering time and it greatly influences dry-matter accumulation. It is possible to increase the grain yield of hybrid rice by planting at early or optimum time of the season (Pan, et al, 1998 and Om, et al., 1996). Under these circumstances, the present study was undertaken to evaluate some physiological characteristics and yield of hybrid rice varieties at different planting dates in A us season.

\footnotetext{
1Sher-e-Bangla A gricultural University, Dhaka-1207, Bangladesh. 2Bangladesh A gricultural University, Mymenshing-2202, Bangladesh. 3Bangladesh Rice Research Institute, Gazipur1701, Bangladesh.

*Corresponding author's email: piash_sau@yahoo.com
} 


\section{MATERIALS AND METHODS}

Two experiments were carried out at the research farm of Sher-e-Bangla Agricultural University, Dhaka and BRRI, Gazipur during (April to July) Aus season 2009 and 2010, respectively induding three hybrids (BRRI hybrid dhan2, Heera2 and Tia) and one inbred (BRRI dhan48) varieties. Four planting dates (1 April, 16 April, 1 May, 16 and 16 May) were selected for each experiment. Both the experiments were laid out in split-plot design with three replications and assigned planting date to the main plot and variety to the sub-plot. The unit plot size was $4 \mathrm{~m} \times 5 \mathrm{~m}\left(20 \mathrm{~m}^{2}\right)$. Twenty-five-day-old seedlings were transplanted maintaining $25 \mathrm{~cm} \times 15 \mathrm{~cm}$ spacing and one seedling hill-1 (for both hybrid and inbred varieties).

Cowdung was applied in unit plot @ $5 \mathrm{t} \mathrm{ha}^{-1}$ and chemical fertilizers such as urea, triple superphosphate, muriate of potash, gypsum and zinc sulphate were applied @ 160, 100, 110, 40 , and $10 \mathrm{~kg} \mathrm{ha}^{-1}$, respectively (BRRI, 2008). Cowdung was applied 15 days before land preparation. All the fertilizers was applied as basal dose except urea, which was applied as top dressing in three equal installments at five days after transplanting (DAT), mid-tillering stage and panide initiation stage. Standard intercultural operation and plant protection measures were taken as and when required. Flag leaf chlorophyll content was estimated according to Witham (1986) and flag leaf photosynthetic rate was measured with a portable photosynthesis system (Model: LI-6400, Li-COR Inc. USA) at 2, 9, 16 and 23 DAF only from the second experiment. Pre-anthesis shoot stem +(leaf) reserve translocation was cal culated by net loss in dry weight of vegetative organs between pre-anthesis and maturity (Bonnett and Incoll, 1992). Data were recorded on yield and yield components at maturity. Daily maximum and minimum temperature of the experimental field was also recorded. The collected data were analyzed using the statistical computer package programme MSTAT-C (Russell, 1986) and the difference between the pairs of treatment mean was adjudged by DMRT.

\section{RESULTS AND DISCUSSION}

\section{Flag leaf chlorophyll content and chlorophyll a:b}

All the test hybrid varieties synthesized and retained significantly higher amount of chlorophyll in their flag leaf at different DAF compared to inbred BRRI dhan48 (Table 1). Heera2 accumulated the highest amount of chlorophyll $\left(2.43 \mathrm{mg} \mathrm{g}^{-1}\right)$ in its flag leaf at 2 DAF while it was the lowest in BRRI dhan48 (1.88). These results were in consistent to Tang et al., (2010) who reported that hybrid rice content higher amount of chlorophyll (SPAD) in their leaves. While Islam et al., (2006) found slightly higher chlorophyll content in the leaf of hybrids compared to inbred BRRI dhan31. Heera2 and BRRI hybrid dhan2 maintained significantly higher chlorophyll a:b in their flag leaf compared to the rest two. Tia exhibited significantly lowest chlorophyll a:b at 2 DAF (2.32) and at 9 DAF (2.07). Flag leaf chlorophyll content and chlorophyll a t b gradually decreased up to $23 \mathrm{DAF}$, irrespective of variety. The chlorophyll a t b in flag leaf declined by about $27 \%$ in hybrids and $41 \%$ in inbred BRRI dhan48 at 23 DAF as compared to 2 DAF. That is, BRRI hybrid dhan2 and Heera2 had higher amount of chlorophyll 'a' in their flag leaf compared to inbred BRRI dhan48 till 23 DAF. These results suggested the higher source used (flag leaf photosynthetic) by Heera2 and BRRI hybrid dhan2 over BRRI dhan48 at post heading stage in A us season.

\section{Flag leaf photosynthetic rate}

Flag leaf photosynthetic rate significantly varied among the varieties at different DAF (Table 2). Maximum photosynthetic rate $\left(33.37 \mu \mathrm{mol} \mathrm{CO}_{2} \mathrm{~m}^{-2} \mathrm{~s}^{-1}\right)$ was recorded in BRRI hybrid 
dhan2 at 2 DAF followed by hybrid Heera2 $\left(32.25 \mu \mathrm{mol} \mathrm{CO}_{2} \mathrm{~m}^{-2} \mathrm{~s}^{-1}\right)$. The inbred BRRI dhan48 exhibited the lowest photosynthesis rate $\left(28.15 \mu \mathrm{mol} \mathrm{CO}_{2} \mathrm{~m}^{-2} \mathrm{~s}^{-1}\right)$ in $2 \mathrm{DAF}$, which was statistically different from Tia $\left(29.87 \mu \mathrm{mol} \mathrm{CO} \mathrm{CO}^{-2} \mathrm{~s}^{-1}\right)$. This finding is partially consistent with Tang et al., (2010) also reported that photosynthetic capability of flag leaf in hybrid rice was higher. Flag leaf photosynthetic rate was the highest at $2 \mathrm{DAF}$ and gradually decreased with the advancement of grain filling period, regardless of variety and planting date. Reduction of photosynthetic rate at the day 9 and 16 after flowering were $21.51 \%$ and $34.20 \%$ in BRRI dhan48 whereas average $37.70 \%$ and $45.52 \%$ in hybrids respectively compared to 2 DAT. Lower reduction of flag leaf photosynthetic rate in BRRI dhan48 probably associated with its efficient sink activities. However, at 23 DAF the rate was significantly higher in BRRI hybrid dhan2 and Heera2 indicating extended grain filling and delayed senescence compared to tia and BRRI dhan48.

Table 1. Flag leaf chlorophyll content and chlorophyll a $\mathbf{t} b$ in hybrid and inbred rice varieties at different planting dates in Aus season 2010

\begin{tabular}{l|cccc|cccc}
\hline \multirow{2}{*}{ Variety } & \multicolumn{3}{c|}{$\begin{array}{c}\text { Total chlorophyll } \\
\text { (mg g-1fresh wt.) }\end{array}$} & & & Chlorophyll at b \\
& 2DAF & 9DAF & $16 \mathrm{DAF}$ & 23DAF & 2DAF & 9DAF & 16DAF & 23DAF \\
\hline BRRI hybrid dhan2 & $2.37 \mathrm{a}$ & $2.31 \mathrm{a}$ & $2.04 \mathrm{a}$ & $1.86 \mathrm{a}$ & $3.12 \mathrm{a}$ & $3.04 \mathrm{a}$ & $2.85 \mathrm{a}$ & $2.30 \mathrm{a}$ \\
Heera2 & $2.43 \mathrm{a}$ & $2.33 \mathrm{a}$ & $2.08 \mathrm{a}$ & $1.78 \mathrm{ab}$ & $3.12 \mathrm{a}$ & $3.12 \mathrm{a}$ & $2.89 \mathrm{a}$ & $2.29 \mathrm{a}$ \\
Tia & $2.34 \mathrm{a}$ & $2.10 \mathrm{~b}$ & $1.86 \mathrm{~b}$ & $1.75 \mathrm{~b}$ & $2.32 \mathrm{c}$ & $2.07 \mathrm{c}$ & $2.07 ?$ & $1.67 \mathrm{~b}$ \\
BRRI dhan48 & $1.88 \mathrm{~b}$ & $1.80 \mathrm{c}$ & $1.51 \mathrm{c}$ & $1.24 \mathrm{c}$ & $2.76 \mathrm{~b}$ & $2.55 \mathrm{~b}$ & $1.73 ?$ & $1.62 \mathrm{~b}$ \\
CV(\%) & 6.50 & 7.59 & 6.61 & 7.17 & 5.67 & 5.33 & 5.47 & 4.89 \\
\hline
\end{tabular}

W ithin a column, values followed by different letters differ at the $5 \%$ level of significance as per DM RT. (Variety $x$ planting daten S

Table 2. Flag leaf photosynthetic rate in hybrid and inbred rice varieties at different planting dates in Aus 2010

\begin{tabular}{l|cccc}
\hline Variety/ planting date & \multicolumn{4}{c}{ Photosynthetic rate $\left(\mu \mathrm{mol} \mathrm{CO}_{2} \mathrm{~m}^{-2} \mathrm{~s}^{-1}\right)$} \\
\cline { 2 - 5 } & $2 \mathrm{DAF}$ & 9DAF & $16 \mathrm{DAF}$ & $23 \mathrm{DAF}$ \\
\hline Variety & & & & \\
BRRI hybrid dhan2 & $33.37 \mathrm{a}$ & $19.62 \mathrm{bc}$ & $18.38 \mathrm{~b}$ & $14.23 \mathrm{a}$ \\
Heera2 & $32.25 \mathrm{a}$ & $20.79 \mathrm{~b}$ & $17.63 \mathrm{~b}$ & $14.28 \mathrm{a}$ \\
Tia & $29.87 \mathrm{~b}$ & $19.09 \mathrm{c}$ & $16.09 \mathrm{c}$ & $12.99 \mathrm{~b}$ \\
BRRI dhan48 & $28.15 \mathrm{c}$ & $22.88 \mathrm{a}$ & $19.18 \mathrm{a}$ & $12.82 \mathrm{~b}$ \\
Planting date & & & & \\
O1April & 31.61 & $24.38 \mathrm{a}$ & $19.46 \mathrm{a}$ & 14.17 \\
16 April & 32.28 & $22.62 \mathrm{a}$ & $18.75 \mathrm{ab}$ & 14.18 \\
01 May & 29.93 & $18.49 \mathrm{~b}$ & $17.09 \mathrm{~b}$ & 13.58 \\
16May & 29.82 & $16.92 \mathrm{~b}$ & $14.98 \mathrm{c}$ & 12.41 \\
CV(\%) & 5.80 & 8.67 & 7.44 & 10.77 \\
\hline
\end{tabular}

Within a column, values followed by different letters differ at the $5 \%$ level of significance as per DM RT. (V ariety $x$ planting daten S)

\section{Shoot dry matter accumulation and its remobilization to grain}

Pre-anthesis shoot DM accumulation became maximum in Heera2 $(24.20 \mathrm{~g} \mathrm{hill-2}$ ) and minimum in Tia (19.94 g hill-2) in 2009. Hybrid varieties tended to accumulated significantly higher amount of dry matter compared to inbred BRRI dhan48 (Table 3). Shoot DM retention at maturity showed almost similar pattern as DM accumulation was noticed in 
hybrid and inbreed varieties at pre-anthesis time. This result indicates that normal growth of these hybrids was not affected up to flowering stage in A us season. The highest shoot reserve translocation was found in inbred BRRI dhan48 $(7.70 \%$ and $8.56 \%)$, which was significantly different from all three hybrid varieties (ranged from $4.83 \%$ to. $2 \%$ ) in the 1 st and 2nd Aus season, irrespective of transplanting date. Shoot dry matter significantly dedined with delayed transplanting regardless of variety. The maximum reduction of shoot reserve translocation was observed in Heera2 (160.23\%) followed by BRRI hybrid dhan2 (136.78\%), Tia (65.29\%) due to delayed transplanting (16 May) in comparison to 1 April transplanted crop. This value was the lowest in inbred BRRI dhan48 (15.92\%). Almost similar result was obtained in second Aus season. The result indicated that the studied hybrids were more sensitive to delayed transplanting in terms of shoot reserve translocation to grain compared to inbred BRRI dhan48.

Table 3. Pre-anthesis dry matter accumulation in shoot and its translocation to the grain of hybrid and inbred rice varieties at different planting dates in Aus 2009 and 2010

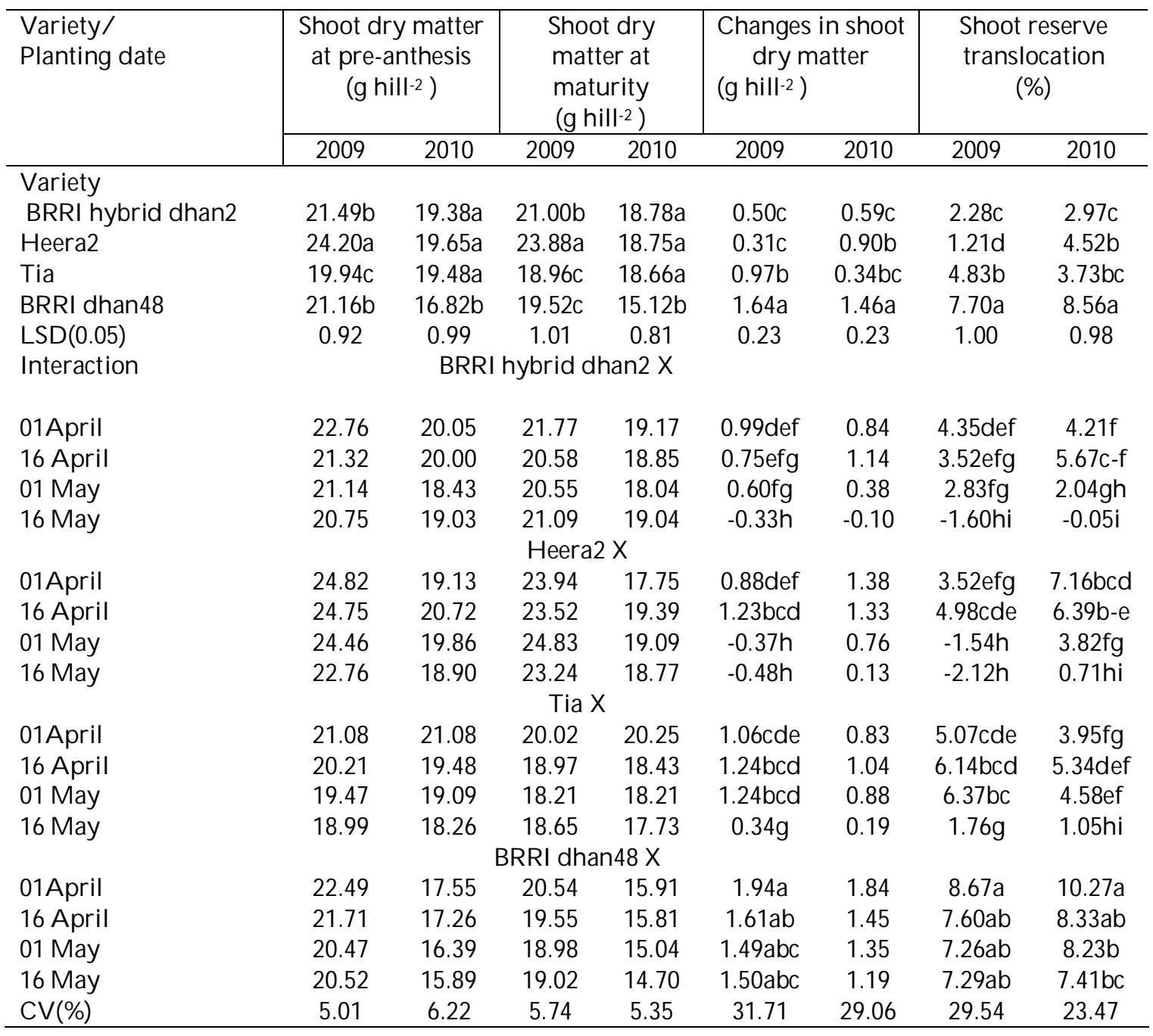

W ithin a column values followed by different letters differ at the $5 \%$ level of significance as per D M RT. 


\section{Relationship between shoot reserve remobilization percent and temperature}

A strongly negative relation exists between minimum temperature (flowering to maturity) and shoot reserve translocation to grain (\%) in all the tested rice varieties (Fig. 1). Shoot reserve remobilization to grain in all the hybrid varieties was more sensitive than the BRRI dhan48 for the minimum temperature. This finding is partially in agreement with Kanno and Makino (2010) who reported that cool night temperature favoured the carbon allocation to panicles.
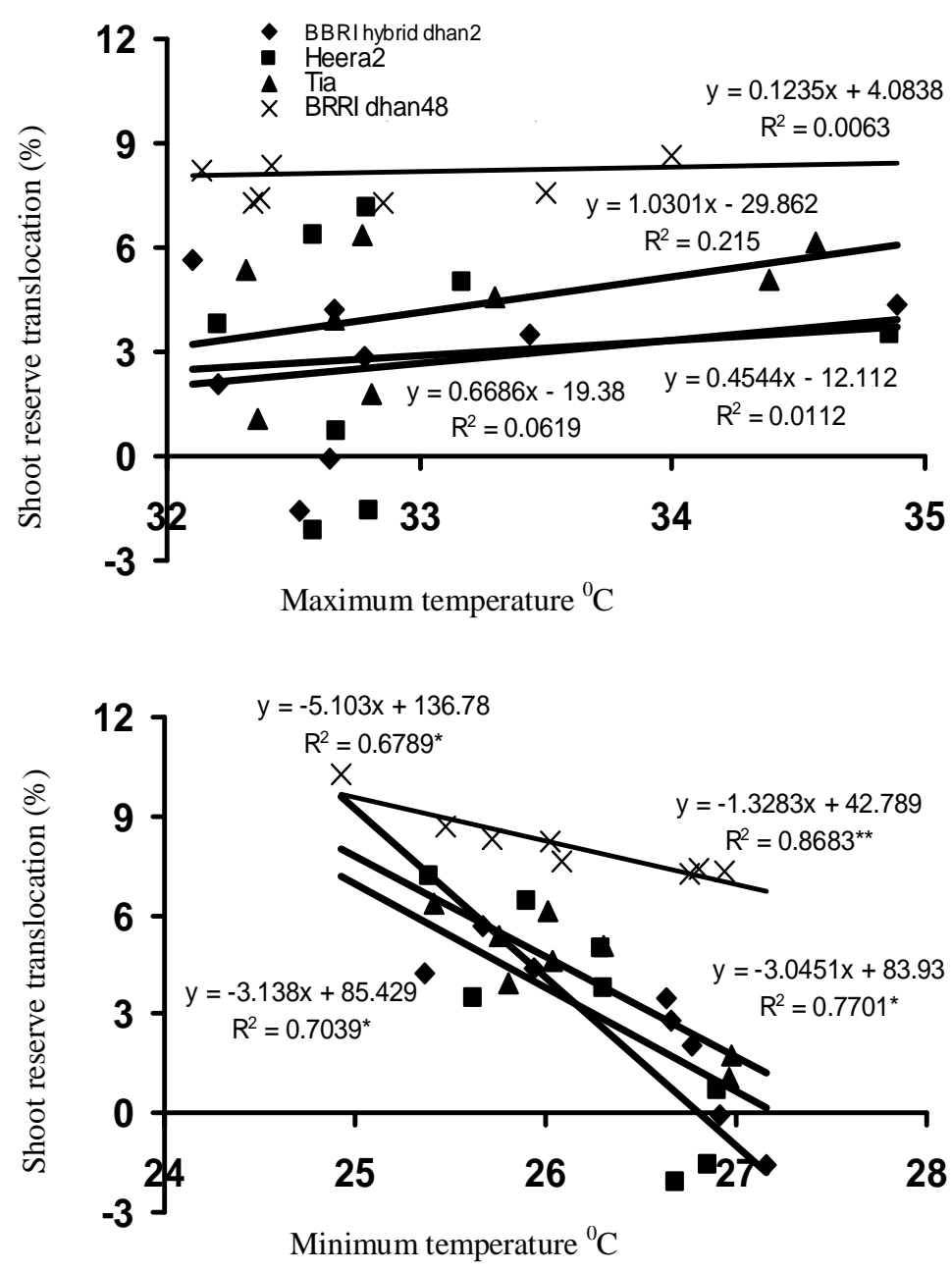

Fig. 1. Relationship between shoot reserve translocation to grain $(\%)$ of the hybrid and inbred rice varieties and air temperature (flowering to maturity) in Aus season. (data of two Aus seasons, 2009 and 2010)

\section{Yield components}

The hybrid varieties produced significantly longer panicle and higher number of spikelets panide ${ }^{-1}$ compared to elite inbred BRRI dhan48 in both A us seasons (Table 4). The variety Hera2 and BRRI hybrid dhan2 had the highest thousand grain weight in the same statistical rank and the lowest grain weight was recorded in BRRI dhan48. Planting date had no significant effect on grain size 1000-grain weight is a genotypic character controlled by 
genetic makeup (Yoshida, 1981). Individual grain weight remained unchanged in the hybrids at delayed planting indicating physiological activity of sink was for temperature rise

Table 4. Yield components of hybrid and inbred rice varieties grown in Aus season 2009 and 2010

\begin{tabular}{l|cc|cc|cc}
\hline Variety & \multicolumn{2}{|c|}{$\begin{array}{c}\text { Panicle length } \\
(\mathrm{cm})\end{array}$} & \multicolumn{2}{c|}{$\begin{array}{c}\text { Spikelets panicle } \\
\text { (no.) }\end{array}$} & \multicolumn{2}{c}{$1000-$ Grain weight } \\
& 2009 & 2010 & 2009 & 2010 & 2009 & 2010 \\
\cline { 2 - 7 } & $24.91 \mathrm{~b}$ & $25.03 \mathrm{~b}$ & $133.8 \mathrm{a}$ & $130.4 \mathrm{a}$ & $25.74 \mathrm{a}$ & $26.17 \mathrm{a}$ \\
BRRI hybrid dhan2 & $25.28 \mathrm{~b}$ & $24.92 \mathrm{~b}$ & $137.1 \mathrm{a}$ & $137.2 \mathrm{a}$ & $25.87 \mathrm{a}$ & $25.68 \mathrm{a}$ \\
Heera2 & $27.52 \mathrm{a}$ & $27.64 \mathrm{a}$ & $135.3 \mathrm{a}$ & $140.3 \mathrm{a}$ & $23.60 \mathrm{~b}$ & $23.66 \mathrm{~b}$ \\
Tia & $23.77 \mathrm{c}$ & $23.45 \mathrm{c}$ & $110.9 \mathrm{~b}$ & $110.5 \mathrm{~b}$ & $22.13 \mathrm{c}$ & $22.18 \mathrm{c}$ \\
BRRI dhan48 & 2.76 & 3.24 & 6.60 & 5.74 & 3.11 & 2.69 \\
CV(\%) & &
\end{tabular}

Within a column, values followed by different letters differ at the $5 \%$ level of significance as per D M RT. (variety $x$ planting datens)

Table 5. Yield and components of the hybrid and inbred rice varieties grown in Aus season 2009 and 2010

\begin{tabular}{|c|c|c|c|c|c|c|c|c|}
\hline \multirow{2}{*}{$\begin{array}{l}\text { Variety/ } \\
\text { Planting } \\
\text { date }\end{array}$} & \multicolumn{2}{|c|}{$\begin{array}{c}\text { Panicles } \\
\mathrm{m}^{-2}\end{array}$} & \multicolumn{2}{|c|}{$\begin{array}{l}\text { Filled spikelets } \\
\qquad \mathrm{m}^{-2}\end{array}$} & \multicolumn{2}{|c|}{$\begin{array}{c}\text { Spikelet filling } \\
(\%)\end{array}$} & \multicolumn{2}{|c|}{$\begin{array}{l}\text { Grain yield } \\
\text { (t ha-1) }\end{array}$} \\
\hline & 2009 & 2010 & 2009 & 2010 & 2009 & 2010 & 2009 & 2010 \\
\hline \multicolumn{9}{|l|}{ Variety } \\
\hline $\begin{array}{l}\text { BRRI hybrid } \\
\text { dhan2 }\end{array}$ & $173.3 \mathrm{C}$ & $200.7 b$ & $7105 d$ & $12012 b$ & $30.17 \mathrm{c}$ & $44.61 b$ & $1.56 \mathrm{~d}$ & $2.27 c$ \\
\hline Heera2 & 187.0b & $201.0 \mathrm{~b}$ & 10856b & 12166b & $40.62 \mathrm{~b}$ & $43.99 \mathrm{~b}$ & $2.51 b$ & $2.56 b$ \\
\hline Tia & $164.7 \mathrm{c}$ & $168.4 \mathrm{C}$ & $8982 c$ & $9286 c$ & $37.38 b$ & $37.85 c$ & $1.92 \mathrm{C}$ & $1.87 d$ \\
\hline BRRI dhan48 & $219.8 a$ & 244.1a & 17103a & 17916a & $69.48 a$ & $65.47 a$ & $3.56 a$ & 3.34a \\
\hline Interaction & \multicolumn{8}{|c|}{ BRRI hybrid dhan2 } \\
\hline 01A pril & $188.2 \mathrm{cde}$ & $218.7 \mathrm{~cd}$ & 12412de & $13523 \mathrm{~cd}$ & $48.43 d$ & 46.97c & 2.77de & $2.49 \mathrm{fg}$ \\
\hline 16April & $177.9 \mathrm{e}$ & $213.8 \mathrm{~d}$ & $6515 \mathrm{~g}$ & 14038bcd & $28.12 f$ & $49,26 c$ & $1.40 \mathrm{~g}$ & 2.57efg \\
\hline 01 May & 177.3e & $204.3 d$ & $5879 g$ & 10280cf & $25.36 f g$ & 38.10de & $1.31 \mathrm{~g}$ & 2.11gh \\
\hline 16 May & $150.7 f$ & 166.Ofgh & $3613 \mathrm{~h}$ & $\begin{array}{l}10203 f \\
\text { eera2 }\end{array}$ & 18.76gh & 44.11cd & $0.74 \mathrm{~h}$ & $1.93 \mathrm{~h}$ \\
\hline 01A pril & 206.3bcd & $215.8 \mathrm{~cd}$ & 18637b & $14741 b c d$ & $65.69 \mathrm{~b}$ & $50.14 c$ & 4.5ab & 3.31abc \\
\hline 16April & 186.8de & $206.4 d$ & 12105de & 14539bcd & $46.68 d$ & $51.71 c$ & $2.95 \mathrm{~cd}$ & $2.88 \mathrm{cdlef}$ \\
\hline 01 May & $201.8 \mathrm{bcd}$ & $213.4 d$ & 988lf & 10403ef & $37.03 e$ & 35.67ef & $2.08 f$ & $2.12 \mathrm{gh}$ \\
\hline 16 May & 153.0f & $168.2 \mathrm{fg}$ & $2799 h$ & $\begin{array}{l}\text { 8961f } \\
\text { Tia }\end{array}$ & 13.11h & 38.44de & $0.51 \mathrm{~h}$ & $1.90 \mathrm{~h}$ \\
\hline 01A pril & 209.9bc & 198.3de & 15821c & 13882cd & 53.81cd & $49.90 \mathrm{c}$ & $3.40 c$ & $3.05 \mathrm{bcd}$ \\
\hline 16April & $176.5 \mathrm{e}$ & 178.3ef & 11715ef & 12797de & $48.05 d$ & $50.89 c$ & 2.62de & 2.66def \\
\hline 01 May & $140.1 f$ & 151.9gh & 4679gh & $6218 \mathrm{~g}$ & $25.27 f g$ & $29.36 f$ & $0.95 \mathrm{gh}$ & $1.10 \mathrm{i}$ \\
\hline 16 May & $132.2 f$ & 145.3h & $3712 \mathrm{~h}$ & $4247 \mathrm{~g}$ & $22.37 f g$ & $21.24 \mathrm{~g}$ & $0.69 \mathrm{~h}$ & $0.65 i$ \\
\hline \multicolumn{9}{|c|}{ BRRI dhan48 } \\
\hline 01A pril & $245.0 \mathrm{a}$ & 246.7ab & $22750 a$ & 20100a & 81.58a & 70.4la & 4.88a & $3.76 a$ \\
\hline 16A pril & $220.0 b$ & $258.7 a$ & 18755b & 19530a & $78.46 a$ & 66.87ab & $4.05 b$ & 3.51ab \\
\hline 01 May & $212.5 b$ & $235.1 b c$ & $14160 \mathrm{~cd}$ & $15601 b c$ & $60.83 \mathrm{bc}$ & $61.82 \mathrm{~b}$ & $2.94 c d$ & $3.11 \mathrm{bcd}$ \\
\hline 16 May & $201.6 b c d$ & $235.8 b c$ & 12747de & 16433b & $57.04 \mathrm{C}$ & 62.79ab & $2.36 € f$ & 2.99cde \\
\hline CV $(\%)$ & 6.99 & 6.15 & 11.36 & 11.24 & 10.14 & 9.52 & 13.02 & 11.19 \\
\hline
\end{tabular}

W ithin a column, values followed by different letters differ at the $5 \%$ level of significance as per D M RT 
in late A us season. Panides $\mathrm{m}^{-2}$ (219.8 and 244.1) and filled spikelets $\mathrm{m}^{-2}$ (17103 and 17916) were markedly higher in inbred BRRI dhan48 compared to all the test hybrid varieties. These two yield contributing characters were rapidly deceased in hybrid varieties compared to inbred BRRI dhan48 in delayed transplanting. Maximum number of panicles $\mathrm{m}^{-2}$ was recorded from BRRI dhan48 at 1 April transplanting (245.0) in first A us season and at 16 April transplanting (258.7) in second A us season. Reduction in number of spikelets $\mathrm{m}^{-2}$ at delayed transplanting associated with poor spikelets filling percent. Yang et al. (2002), Ao et al., (2008) and Yang and Zhang (2010) reported that poor spikelet filling is a problem in hybrid rice varieties. The maximum spikelets filling (69.48\% and $65.47 \%$ ) was found in 2009 and 2010 of inbred variety BRRI dhan48, irrespective of transplanting date, which was statistically higher than that of all the three hybrid varieties. The extent of reduction of grain filling percentage was higher in all the tested hybrid rice varieties $(49.82 \%)$ compared to inbred BRRI dhan48 (21.12\%) when transplanting date shifted from 1 A pril to 16 May. This might be due to the poor adaptability of test hybrid rice varieties to climate of late Aus season.

\section{G rain yield}

Irrespective of transplanting dates, inbred BRRI dhan48 (3.56 t ha ${ }^{1}$ and $3.34 \mathrm{t} \mathrm{ha}^{-1}$ ) out yielded the studied hybrid rice varieties by producing $36.7 \%$ (average) higher grain yield in each A us season (Table 5) attributed by higher number of panides $\mathrm{m}^{2}$ and higher spikelets filling percent. This result is consistent with findings of Horie et al., (1997) and Ying et al., (1998) who mentioned that yields of hybrid rice varieties are very much unstable across environment. It is apparent form the table that grain yield gradually decreased in delayed transplanting. The highest grain yield (4.88t $\mathrm{ha}^{-1}$ and $\left.3.76 \mathrm{t} \mathrm{ha}^{-1}\right)$ was achieved from BRRI dhan48 at 1 April transplanting, which was statistically at par with Heera2 (4.50 $\mathrm{t} \mathrm{ha}^{-1}$ and $3.31 \mathrm{t} \mathrm{ha}^{-1}$ ) at same transplanting date in both A us seasons. On average, the grain yield reduction was the maximum $(79.22 \%)$ in Tia at 16 May transplanting compared to 1 A pril transplanting while it was $49.23 \%, 68.89 \%$ and $38.08 \%$ in BRRI dhan2, Heera2 and BRRI dhan48 respectively i.e grain yield of inbred BRRI dhan48 was relatively stableat different planting dates in A us season.

\section{CONCLUSION}

In A us season, all the studied hybrids had better vegetative growth up to heading stage but failed to provide desirable grain yield due to poor shoot reserve remobilization to the grain and inefficient photosynthetic activity of flag leaf. This poor shoots reserve remobilization in the test hybrids was associated with their higher sensitivity to rising of minimum temperature at grain filling period.

\section{ACKNOWLEDGEMENT}

We are grateful to the Ministry of Science and Technology, The People's Republic of Bangladesh for their financial support to conduct this research work.

\section{REFEREN CES}

Ao, H, S Wang, Y Zou, S Peng, Q Tang, Y Fang, Y Chen, C Xiong and A Xiao. 2008. Study on yield stability and dry matter characteristics of super hybrid rice. Sci. Agric. Sin., 41:1927-1936.

BBS (Bangladesh Bureau of Statistics). 2011. Statistical yearbook of Bangladesh, Stat. Div, Ministry of Planning, Govt. of the People's Repub. of Bangladesh, Dhaka, www.bbs.gov.bd

Bhuiyan, N I. 2002. The hybrid rice programme for Bangladesh. In: 'Hybrid Rice in Bangladesh: Progress and Future Strategies'. pp. 3-5, proceeding of the first national 
workshop on research and development of hybrid rice in Bangladesh. 5-6 January, Bangladesh Rice Res. Inst., Gazipur, Publication no. 138.

Bonnett, G D and L D. Incoll. 1992 The potential pre-anthesis and post-anthesis contribution of stem internodes to grain yield in crop of winter barley. Ann. Bot. 69: 219-225.

BRRI. 2008. Adunik Dhaner Chash (Modern rice cultivation). 6th edition Booklet no. 5, Bangladesh Rice Res. Inst. Joydebpur, Gazipur. 7: 9-10.

Horie, T, M Ohnishi, J F Augus, L G Lewin, T Tsukaguchi and T. Matano. 1997. Physiological characteristics of high-yielding rice inferred from cross location experiments. Field Crop Res., 52(1-2):55-67.

Islam, M S. 2006. Effect of nitrogen management on growth and yield of hybrid and inbred rice varieties. PhD thesis, Department Agronomy, BAU, Mymensingh, Bangladesh.

Julfiquar, A W. 2009. BRRI: Research and development of hybrid rice. In: 'The Guardian'. Regd no. DA 816. Vol XIX. Issue 3. 3 May 2009. Bangladesh. p.33.

Kanno, K and A. Makino. 2010. Increased grain yield and biomass allocation in rice under cool night temperature. Soil Sci Plant N utr., 56(3): 412-417.

Kumar, R M, S V Subbaiah and K G Pillai. 1998. Response of rice hybrids to different dates of planting in vertisols of Andhra, Pradesh, India. Oryza, 35(3): 258-287.

Longping, Y. 2004. Hybrid rice for food security in the world. FAO Rice conference 04/ CRS.21, Rome, Italy. 12-13 February 2004.

Masum, M. 2009. Impact of hybrid rice on Bangladesh. In: 'The Guardian'. Regd no. DA 816. Vol. XIX. Issue 3. 3 May 2009. Bangladesh. pp. 56-58.

Om, H, SK Katyal, SD Dhiman and A. Singh. 1996. Effect of planting times on hybrid rice in Haryana, India, Int. Rice Res. N otes. 21. 2-3, 74-75.

Pan, X, W Qu and X B Pan. 1998. A nalysis on the main agronomic characters and discussion on high yield breeding of early indica Hybrid rice. Indian J. Agron., 43 (1): 68-70.

Russell, D F. 1986. MSTAT-C Package Program. Department of Crop and Soil Science, Michgan State University, USA.

Sarker, A B S, M B Rahman, M G Ali, M A Manan, R Yasmeen and M A Islam. 2008. Effect of crop establishment methods on the performance of transplanted A man rice in northwestern region of Bangladesh. Bangladesh Rice J. 13 (1): 107-112.

Tang, W. B., G L Zhang, Y H Xiao, H B Deng, K Fan, Liu, G H and LY Chen. 2010. Physiological and bi ochemical characteristics in flag leaves of the $C$ Liangyou series of rice hybrid combinations at late growth stages .Rice Res., 17 (3) : (Chinese J. Rice Sci. 24 (2):169-174.

Witham, H., D F Blaydes and R. M. Devlin. 1986. Exercises in Plant Physiology. 2nd ed. PWS Publishers, Boston. USA. pp 128-131.

Yang, J and J Zhang. 2010. Grain-filling problem in super rice, J. Expt. Bot., 61(1): 1-5.

Yang, L, S Peng, Z Zang, Z Wang, R M Vesperas and Q. Zhu. 2002. Grain and dry matter yields and partitioning of assimilates in japonical indica hybrids. Crop Sci. B, 42: 766772.

Ying, J, S, Peng, G Yang, N Zhou, R M Visperas and K G Cassman. 1998. Comparison of high-yield rice in tropical and sub tropical environments. I. Determinants of grain and dry matter yields. Field Crops Res., 57(1): 85-93.

Yoshida, S. 1981. Fundamentals of rice crop science.Intl.Rice Res. Inst., Los Banos, Leguna, Philippines. p 48-269. 